\title{
Participação da pessoa com deficiência intelectual e síndrome de Down nas Paralimpíadas: o direito à visibilidade
}

https://doi.org/10.11606/issn.1981-4690.v35i3p77-87

\section{Resumo}

Os Jogos Paralímpicos são atualmente o momento de maior visibilidade da eficiência das pessoas com deficiência por meio doesporte. A participação das pessoas com deficiência intelectual nas Paralimpíadas tem sido bem menor que das pessoas com deficiência sensorial ou motora. Eas pessoas com síndrome de Down tem sido excluídas desse evento. Esse artigo tem como objetivo analisar o direito à visibilidade e participação das pessoas com deficiência intelectual e síndrome de Down nas Paralimpíadas. Trata-se de uma pesquisa qualitativa-descritiva realizada pormeio dequestionário com responsáveis da confederação de esportes para pessoa com deficiência intelectual no Brasile Espanha. Verificou-se que as pessoas com deficiência intelectual apresentam menos participação e as pessoas com síndrome de Down não estão participando das paralimpíadas. Conclui-se que a participação nas paralimpíadas trata-se de um direito que além de garantir o direito ao movimento e ao esporte, pode proporcionar maior visibilidade dessas pessoas e possíveis mudanças de preconceitos.

Palavras-Chave: Direitos humanos; Deficiência intelectual; Esporte.

\section{Introdução}

O preconceito que as pessoas com deficiência intelectual e síndrome de Down sofrem dificultam que essas exerçam sua cidadania. Muitas oportunidades não são dadas por acreditar que essas pessoas são incapazes. Assim a participação dessas pessoas em eventos que podem modificar a visão da sociedade deve ser estimulada e oportunizada, minimizando práticas como a infantilização e o capacitismo ${ }^{1}$.

Os Jogos Paralímpicos são atualmente o momento de maior visibilidade da eficiência das pessoas com deficiência por meio do esporte, esse evento é o segundo maior evento multiesportivo em número de participantes e países, apesar de ainda ter menos visibilidade que os Jogos Olímpicos ${ }^{2}$. A participação das pessoas com deficiência intelectual nesse evento tem sido bem menor que das pessoas com deficiência sensorial ou motora, e a participação das pessoas com síndrome de Down não tem acontecido.

O esporte paralímpico norteia seu sistema de classificação baseado no Código de Classificação ${ }^{3}$. Esse prevê que a classificação deve nortear os esportes em dois elementos centrais, sendo esses as deficiências elegíveis para o esporte e que o atleta deverá ser colocado em uma classe baseada na sua capacidade de desempenhar perguntas específicas das habilidades fundamentais do esporte. No primeiro requisito são elegíveis para os esportes 10 deficiências, sendo essas Força Muscular Limitada, Deficiência em membros, Diferença no comprimento de pernas, Baixa estatura, Hipertonia, Ataxia e Atetose, Limitação de amplitude de movimento passivo, Deficiência visual e Deficiência Intelectual ${ }^{4}$.
*Universidade Federal de Goiás, Goiânia, GO, Brasil.

* * Universidade Pontifícia Comillas, Madrid, Espanha. *** Universidade Estadual de Goiás, Goiânia, GO, Brasil.

**** Universidade Estadual de Campinas, Campinas, SP, Brasil. *****Universidade Federal de São Paulo, São Paulo, SP, Brasil. 
No programa de esportes atual dos Jogos Paralímpicos temos atualmente 22 modalidades, sendo que apenas três destas modalidades (Atletismo, Natação, Tênis de Mesa) tem classes elegíveis para a participação da pessoa com deficiência intelectual ${ }^{5}$. A Política de Elegibilidade do IPC prevê que para competir em eventos paralímpicos o atleta com deficiência intelectual deve apresentar "limitaçâo da funcionalidade intelectual e comportamento adaptativo como como expresso em habilidades conceituais, sociais e práticas. Com origem da deficiência antes dos 18

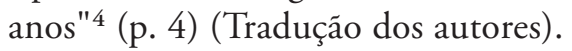

Cada uma das três modalidades oferece apenas uma classe para as pessoas com deficiência intelectual, considerando apenas aspectos associados a função cognitiva de resolução de problema tais como ritmo de corrida ${ }^{6}$ ou habilidade no tênis de mesa ${ }^{7}$. A estrutura atual da classificação esportiva para essa população não segue o mesmo conceito utilizado para outros grupos como na deficiência visual, para esse em todos os esportes são apresentadas 3 classes funcionais, dividindo os atletas naqueles que são cegos e os com baixa visão, sendo esse segundo grupo dividido em sua funcionalidade ${ }^{8}$. Esse cenário não considera os aspectos associados a diversidade biológica dos atletas com deficiência intelectual no que tange a etiologia da deficiência, mas não considera, por exemplo, o impacto das síndromes nas respostas do comportamento adaptativo e habilidades práticas na formulação de possíveis classes. Outro fato que tem sido questionado é que, apesar de poder entrar como pessoa com deficiência intelectual, nenhuma pessoa com síndrome de Down foi classificada em nenhum dos Jogos Paralímpicos. A síndrome de Down é a alteração genética mais frequente no mundo, que causa uma deficiência intelectual e apresenta fenótipos específicos.
Essas características incluem dificuldades motoras resultantes da hiper flexibilidade articular e hipotonia muscular presente nessas pessoas? Assim, essas pessoas não têm vivenciado uma competição justa, em uma mesma classe com pessoas com deficiências intelectual que não tenham as mesmas dificuldades motoras, e ficaram excluídas dos Jogos Paralímpicos.

Sabe-se que a atividade física é capaz de melhorar a condição física da pessoa com síndrome de Down como: força muscular ${ }^{10}$, capacidade cardiorespiratória ${ }^{11}$, composição corporal ${ }^{12}$, equilíbrio ${ }^{13}$, coordenação intermuscular ${ }^{14}$. Sabese também que a pessoa com síndrome de Down pode demonstrar eficiência no esporte quando a oportunidade lhe é dada. Um exemplo desse fato é a atuação da Seleção Brasileira com síndrome de Down campeóes mundiais em $2019^{15}$.

Esse fato tem sido observado pelo Comitê Paralímpico Brasileiro que em 2019 criou uma classe específica para pessoas com síndrome de Down nos Jogos Paralímpicos Escolares ${ }^{16}$, resultando na participação de cinquenta e cinco jovens atletas com síndrome de Down que disputaram em classes específicas na natação e atletismo, demonstrando a necessidade de se efetivar uma avaliação mais justa para inclusão dessas pessoas no esporte competitivo para pessoas com deficiência.

Outro fato que pode confirmar a necessidade de estudos que reflitam para maior efetivação da participaçáo das pessoas com deficiência intelectual no Jogos Paralímpicos e no esporte de alto rendimento é a escassez de estudos que pode ser verificada no banco de dados como no Capes Periódicos. Em uma rápida pesquisa sobre esporte e deficiência intelectual encontramos apenas 37 artigos e nenhum deles analisava ou discutia a participação no esporte de Alto rendimento das pessoas com deficiência intelectual.

\section{Método}

Esse artigo apresenta uma pesquisa qualitativa, por meio de estudo observacional transversal descritivo. $\mathrm{O}$ estudo teve como objeto discutir sobre a participação das pessoas com deficiência intelectual e síndrome de Down nos Jogos Paralímpicos.

Realizou-se uma pesquisa por meio de questóes abertas, por questionário/entrevista coletado pelo Google formulários em junho de 2021, com o diretor técnico da Confederação Brasileira de Desportos para Deficientes Intelectuais (CBDI) e com o Diretor de Esportes da Federaçáo Espanhola de Esportes para Pessoas com Deficiência Intelectual (FEDDI). Essas duas instituições foram escolhidas por serem as maiores representando dos esportes para pessoas com deficiência intelectual nos dois países.

Sobre o perfil dos pesquisados pudemos verificar 
que são pessoas com ampla experiência com o esporte competitivo para pessoas com deficiência intelectual. O diretor técnico da CBDI (D. CBDI) possui 25 anos de experiência nessa instituição acompanhando as pessoas com deficiência intelectual, desde o esporte escolar até o alto rendimento, nas competiçôes regionais, nacionais, internacionais e nas Paralimpíadas. Possui experiência anteriores com pessoas com deficiência intelectual, que se iniciou com sua atuaçáo em 1991 na APAE, passando por diversos cargos na instituição, também trabalhou em escola especial, na Secretaria de Esportes de São Paulo e na Associação de Esporte para Deficientes Intelectuais do estado de São Paulo. Atualmente faz parte do conselho técnico de classificação e elegibilidade do Comitê Paralímpico Brasileiro (CPB) e é presidente da Virtus Americas, ligada

\section{Resultados}

\section{A dificuldade de avaliação da deficiência intelectual e a exclusáo nos jogos paralímpico}

Hoje a avaliação da deficiência intelectual nas Paralimpíadas é realizada por meio do resultado total do QI menor ou igual a 75, em conjunto com limitaçóes significativas no comportamento adaptativo e ser diagnosticados antes dos 18 anos de idade ${ }^{18}$. A avaliação da deficiência visual ou física é baseada em avaliações objetivas, por meio de comprovação de déficits oftalmológicos e físicos claros. O que não aconteceu com a Deficiência intelectual que por ser mais complexa e nem sempre objetiva dificulta a classificação, fato que resultou em fraude nas Paralimpíadas de Sidney em 2000 e exclusão das pessoas com deficiência intelectual dos Jogos Paralímpicos ${ }^{19}$.

Las personas con DI fueron excluidas del movimiento Paralímpicos porque el presidente de la federación española introdujo en los equipos nacionales algunas personas sin discapacidad. Lamentablemente hoy día las personas con DI siguen pagando la mala actuación de esta persona, ya que el contexto actual de participación en los JJPP para personas con DI es extremadamente reducido (D. FEDDI). ${ }^{19}$

O diretor do CBDI completa dizendo que esse fato se tratou de "uma das maiores fraudes do a Virtus Internacional, hoje representando o esporte para pessoas com deficiência intelectual em nosso continente.

O Diretor de Esportes da Federação Espanhola de Esportes para Pessoas com Deficiência Intelectual (D. FEDDI) exerce atividades na instituição há 14 anos como diretor técnico, organizando e dirigindo numerosos campeonatos nacionais e apoiando campeonatos internacionais, tanto da Virtus como do IPC. É licenciado em Ciências da Atividade Física e Esporte, mestre em direito desportivo e gestáo de entidades desportivas e colabora com a fundação da Liga Profissional de Futebol em questôes de classificação.

A análise qualitativa dos dados se pautou na técnica de análise de conteúdo ${ }^{17}$, que permitiu a categorização que deu origem aos subitens da apresentação dos resultados desse artigo.

esporte mundial" que aconteceu na modalidade de basquete onde 12 pessoas sem deficiência intelectual participaram e foram campeóes paralímpicos em Sidney 2000, resultando em 12 anos de exclusão das pessoas com deficiência intelectual dos Jogos Paralímpicos. Relatou ainda que:
A fraude só foi revelada em novembro de 2000 pelo jornalista Carlos Ribagorda que fez parte da equipe afirmou em uma matéria da revista Capital da Espanha que fizeram a frade para "obter grandes resultados e ganhar melhores patrocínios". Não ouve punição com pena de prisão para nem um evolvido até a presente data, em 2013 a justiça da Espanha condenou o senhor Martin Vicente presidente da federação espanhola ao pagamento de 124.000 euros (cerca creca de $421 \mathrm{mil}$ reais em 2013) por uso de subsídio governamental a atletas não deficientes $(\mathrm{D} \text {. CBDI })^{19}$.

Burns ${ }^{14}$ relata que apenas em 2012 em Londres os atletas com deficiência intelectual puderam retornar aos Jogos Paralímpicos, após muitas pesquisas e nova classificação baseada em evidências 118 atletas com deficiência de diversos países puderam competir no atletismo, natação e tênis de mesa.

A reinclusão nas paraolimpíadas só iria acontecer no 
ano de 2012 em Londres foi um processo longo de negociações entre Virtus a Federação Internacional para Deficientes Intelectuais e Comitê Paraolímpico Internacional IPC. Virtus se comprometeu a modificar seu processo de avalição e inclusão de atletas e estabeleceu um processo de estudo periódico para melhor e acompanhar os estudos científicos da deficiência Intelectual (D. CBDI). ${ }^{19}$

Segundo o diretor do FEDDI essa modificação e aprimoramento foi realizado e em 2009 o ICP aprovou em assembleia a inclusão dos atletas com deficiência intelectual, onde essas pessoas teriam que "passar por diversos filtros e serem credenciados por diversas pessoas e entidades". Assim reinclusão das pessoas com deficiência intelectual nos Jogos Paralímpicos aconteceu em 2012 em Londres, dessa forma Atenas em 2004 e Pequim em 2008 não tivemos participação de atletas com deficiência intelectual.

\section{Participação das pessoas com deficiência intelectual e Síndrome de Down no esporte competitivo}

O menor número de atletas com deficiência intelectual em relação às demais deficiências é observada nas principais competiçôes nacionais no Brasil com predominância de $65,5 \%$ de atletas com deficiência física, seguida por $25,1 \%$ de atletas com deficiência visual $(25,1 \%)$ e apenas $9,4 \%$ de pessoas com deficiência intelectual participantes ${ }^{18}$.

Verificamos no relato dos nossos pesquisados que esse fato se repete no número de participantes com deficiência intelectual no número de participantes dos Jogos Paralímpicos, e com o número de atletas espanhóis e brasileiros, conforme TABELA 1.

TABELA 1 - Número de participantes com deficiência intelectual.

Fonte: IPC, 2021.

\begin{tabular}{|c|c|c|c|c|c|c|c|c|c|c|}
\hline \multicolumn{2}{|c|}{ Jogos Paralímpicos } & \multirow{3}{*}{$\begin{array}{l}\text { Total } \\
3843\end{array}$} & \multirow{3}{*}{$\begin{array}{c}\text { Total DI } \\
247\end{array}$} & \multirow{3}{*}{$\begin{array}{c}\text { Total SD } \\
00\end{array}$} & \multirow{2}{*}{$\begin{array}{l}\text { País } \\
\text { Brasil }\end{array}$} & \multirow{2}{*}{$\begin{array}{c}\text { Total } \\
\text { part. }\end{array}$} & \multirow{2}{*}{$\begin{array}{l}\text { DF } \\
39\end{array}$} & \multirow{2}{*}{$\frac{\text { DV }}{10}$} & \multirow{2}{*}{$\begin{array}{c}\text { DI } \\
15\end{array}$} & \multirow{2}{*}{$\begin{array}{l}\text { SD } \\
00\end{array}$} \\
\hline & & & & & & & & & & \\
\hline 2000 & Simey & & & & Espanha & 207 & 102 & 96 & 09 & 00 \\
\hline \multirow{2}{*}{2012} & \multirow{2}{*}{ Londres } & \multirow{2}{*}{4237} & \multirow{2}{*}{120} & \multirow{2}{*}{00} & Brasil & 181 & 128 & 51 & 02 & 00 \\
\hline & & & & & Espanha & 141 & 89 & 49 & 03 & 00 \\
\hline \multirow{2}{*}{2016} & \multirow{2}{*}{ Rio de Janeiro } & \multirow{2}{*}{4350} & \multirow{2}{*}{125} & \multirow{2}{*}{00} & Brasil & 285 & 223 & 60 & 03 & 00 \\
\hline & & & & & Espanha & 127 & 73 & 50 & 04 & 00 \\
\hline
\end{tabular}

Na TABELA 1 pudemos confirmar nossa hipótese de menor participação da deficiência intelectual em relação às demais e a exclusão das pessoas com síndrome de Down. Se considerarmos o número total de participantes dos Jogos Paralímpicos de 2000, 2012 e 2016 verificamos que tivemos $7,06 \%, 2,83 \%$ e $2,87 \%$ respectivamente de atletas com deficiência intelectual. Quanto ao número de participantes com síndrome de Down dos três Jogos Paralímpicos citados não tivemos nenhum participante com síndrome de Down em 2000, 2012 e 2016.

Verificamos ainda a baixa participação das pessoas com deficiência intelectual em relação a deficiência visual e física tanto considerando os atletas do Brasil e da Espanha. Os atletas com deficiência intelectual da Espanha eram apenas 4,34\% em 2000, 2,12\% em 2012 e 3,14\% em 2016 em relação aos demais atletas participantes. No Brasil tivemos 23,43\% em 2000, 1,10\% em 2012 e 1,05\% em 2016 de atletas com deficiência intelectual em relação aos demais participantes com deficiência visual e física. $\mathrm{O}$ maior número de atletas brasileiros em Sidney em 2000 se deu pela participação do time de basquete em cadeira de rodas que por ser um esporte coletivo permite um número maior de participação. Com a exclusão do basquete em cadeira de rodas a partir da fraude em Sidney e não inclusão de nenhum esporte coletivo, conjuntamente com a adoção de classe única na deficiência intelectual, favoreceu ainda mais a redução da inclusão de pessoas com deficiência intelectual nos Jogos Paralímpicos. 
TABELA 2 - Número de participantes com deficiência intelectual por categoria.

\begin{tabular}{llcccccc}
\hline Jogos / Ano & \multicolumn{1}{c}{ País } & Total DI & Nataçáo & Atletismo & Basquete & Tênis de mesa & Hipismo \\
\hline \multirow{2}{*}{ Sidney 2000 } & Brasil & 15 & 00 & 01 & 12 & 02 & 00 \\
\cline { 2 - 8 } & Espanha & 09 & 03 & 05 & 00 & 00 & 01 \\
\hline \multirow{2}{*}{ Londres 2012 } & Brasil & 02 & 01 & 00 & -- & 01 & -- \\
\cline { 2 - 8 } & Espanha & 03 & 01 & 02 & -- & 00 & -- \\
\hline \multirow{2}{*}{ Rio de Janeiro 2016 } & Brasil & 03 & 02 & 01 & -- & 00 & -- \\
\cline { 2 - 8 } & Espanha & 04 & 01 & 02 & -- & 01 & -- \\
\hline
\end{tabular}

Outro dado que chamamos atenção na nossa pesquisa presente nas duas tabelas é a não participação das pessoas com síndrome de Down nos Jogos Paralímpicos. Burns ${ }^{14}$ estudou o impacto da deficiência intelectual no esporte de alto rendimento e apresenta diversos estudos que mostram as diferenças de performance das pessoas com deficiência intelectual e com síndrome de Down. Segundo o autor, como já dissemos, para além da deficiência intelectual a pessoa com síndrome de Down apresenta diferenças antropométricas e biomecânicas, como altura, circunferência do membro, gordura corporal, marcha ampla, hipotonicidade muscular e hipermobilidade das articulaçôes, além de diferenças cardíacas e respiratórias que resultam em menor consumo máximo de oxigênio $\left(\mathrm{VO}_{2 \max }\right)$ do que a população média e aqueles com outros tipos de deficiência intelectual ${ }^{15}$. Apresentam também menor coordenação intermuscular ${ }^{10}$, assim como pior equilíbrio?.

Os esportes paralímpicos agrupam atletas com deficiências semelhantes para garantir que as disputas sejam justas e equilibradas. Este processo é chamado de Classificação. Ser inelegível não significa que o atleta não tenha uma deficiência, significa somente que a deficiência específica ou comprometimento náo se enquadra na modalidade em questáo. O processo de classificação e elegibilidade para deficiência intelectual e realizado através de laudos e relatório adaptativo realizado por psicólogos especializados. A Virtus tem feito estudos baseados nesses critérios para ampliar o número de atletas nas paraolimpíada isso ajuda na orientação técnica e assim ajudar na ampliação (D. CBDI).

Segundo nosso pesquisado da CBDI "a participação do $S D$ não é vetada em eventos internacionais onde estão envolvidos os deficientes intelectuais, em todos os eventos de comitês paraolímpicos ou federação nacionais que estão presentes não há oficialmente qualquer proibição bastando o atleta ter o índice da prova". No entanto o fato de nenhuma pessoa com síndrome de Down ter participado ainda de nenhuma das ediçóes dos Jogos Paralímpicos mostra que essa possibilidade não tem sido justa.

\section{Dificuldade de participaçáo de eventos competitivos internacionais das pessoas com Síndrome de Down}

A desigualdade e injustiça do fato das pessoas com síndrome de Down disputarem vaga nos Jogos Paralímpicos com as pessoas com deficiência intelectual, sem hipotonia e as demais características da síndrome de Down, é apontada por movimentos como de Algarve ${ }^{16}$.

Outro movimento contrário à exclusão das pessoas com Síndrome de Down aconteceu em novembro de 2019 quando nas Paralimpíadas Escolares brasileira, que teve a participação de 1231 recordes de atletas, e quando foi criada uma classe específica para pessoas com síndrome de Down na natação e no atletismo 09, que acabavam sendo excluídas de outras ediçóes por disputarem vagas com as demais pessoas com deficiência intelectual e vivenciavam a exclusão como acontece nos Jogos Paralímpicos. 
Nas Paraolimpíadas não temos atletas com síndrome de Down, o que temos são iniciativas de alguns países no sentido de desenvolver inclusão dos SD em suas competições um bom exemplo foi a inclusão na paraolimpíada escolar nacional brasileira (D. CBDI).

Querido et $\mathrm{al}^{17}$ relatam que as pessoas com síndrome de Down, mais especificamente os nadadores, podem competir nos Jogos Paralímpicos e eventos promovidos pelo Comitê Paralímpico Internacional juntamente com nadadores com deficiência intelectual na Classe S14. Mas os autores chamam atenção que "até ao momento, nenhum nadador com SD conseguiu alcançar níveis de performance que lhe permitisse participar num evento Paralímpico" (p. 38) ${ }^{17}$.

Tanto a CBDI quanto a FEDDI reconhecem o problema de exclusão das pessoas com síndrome de Down dos Jogos Paralímpicos e procuram incentivar as competiçóes para esses atletas no Brasil e na Espanha:

En FEDDI tanto en atletismo como en natación se realiza una clase de competición solo para síndrome Down compitiendo entre ellos en estas dos especialidades deportivas. En FEDDI desde que en 2017 VIRTUS comenzó a desarrollar una clase de participación para personas con síndrome down y/o ahora un "additional impairmemt", la.federacion ha apostado por qué los deportistas con síndrome down tengan su contexto de participación internacional en este ambito. Se considera que a futuro es la vía que podrá permitir a estos deportistas estar presentes en algún momento en los JJPP (D. FEDDI).

A CBDI confederação brasileira de desportes para deficientes intelectuais entidade filiada ao $\mathrm{CPB}$ e a Virtus Internacional sempre estimulou a competição entre os SD colocando provas exclusivas e separando o SD 21 dos indivíduos SD com mosaicismo. O trabalho da CBDI tem sido uma prova de que o esporte para $\mathrm{SD}$ tem características próprias e que deve ser estimulado, das 13 modalidades desenvolvidas pela instituiçáo todas podem ter competiçôes próprias para SD um exemplo de investir e ter sucesso e a seleção brasileira de futsal para SD campeã mundial e referência em todo mundo (D. CBDI).
Segundo a CBDI a organização e participação de atletas com síndrome de Down no Brasil em competiçóes no Brasil se dão em especial nas olimpíadas das Apaes que "que por sua característica de entidade com um número considerável de SD tem em suas competiçóes nacionais a participação ativa desses atletas" (D.CBDI), e a olimpíada especial.

As olímpiadas esportivas das Apaes e as olimpíadas especiais têm um trabalho muito significativo na iniciação esportiva de um número significativo de pessoas com deficiência intelectual no esporte. Leitão ${ }^{18}$ lembra que muitas pessoas com deficiência intelectual ainda estão "são inativas por falta de estímulos socioculturais e, algumas vezes, ainda são subestimadas, principalmente com relação à prática de esportes" (p. 1) ${ }^{18}$, e que as olimpíadas especiais têm como objetivo "dar oportunidades de participaçáo a todos, mesmo para as pessoas com maior comprometimento motor. Além disso, procura valorizar o que cada um consegue realizar, pois suas provas são divididas por níveis equitativos de habilidades" (p. 96) ${ }^{18}$. Acreditamos que esses eventos são muito relevantes e devem continuar existindo, mas não substituem a participação das pessoas com deficiência intelectual nos Jogos Paralímpicos.

Sobre a participação das pessoas com síndrome de Down em eventos esportivos internacionais o diretor da CBDI relata:

A Sport Union for Athletes with Down Syndrome realizou em 2016 em Firenze Itália o primeiro Trissome Games com a presença de 800 atletas e 34 países mostrando a força do movimento para pessoas com SD, esse trabalha e fruto de anos de dedicaçáo e a criação da Dsiso voltada a nataçáo onde os países cogitavam fazer uma competição de múltiplos esportes voltada só para SD. Além da AWDS existe outras duas importantes federaçóes uma já citada a Dsiso e a outra e Federação internacional de Futebol para SD (D. CBDI).

As competiçóes nacionais e internacionais específicas para competiçóes para pessoas com síndrome de Down são positivas, pois permitem um maior número de participantes. No entanto não excluem a necessidade de se repensar a avaliação da deficiência intelectual nos eventos de maior visibilidade no mundo para inclusão 
dos atletas de alto rendimento com síndrome de Down.

En las competiciones de VIRTUS los deportistas con DI se clasifican en las clases II1, II2 e II3 (trial group) En la II1 únicamente se valora la elegibilidad del deportista pero se establece una diferenciación entre ellos en base a los criterios de elegibilidad. Parece lógico pensar, y así se realiza en los diferentes organismos que trabajan en definir la DI, que el objetivo debería ser realizar una diferenciación de grupos en base a estos criterios de elegibilidad que son realmente los que definen la DI. En la II2, se definen como personas con DI con un additional impairmemt. El cual actualmente se valora mediante un nuevo cuestionario aprobado por VIRTUS y dónde se engloban a los deportistas con síndrome de down. Como he comentado anteriormente, parece lógico plantear, como ocurre en otras discapacidades, que la clasificación de deportistas con DI en diferentes clases/grupos debería estar basada en los criterios que definen la elegibilidad del deportista. De esta manera se podría establecer, al igual que ocurre en otras discapacidades esas clases bajas y/o con una mayor discapacidad y además esas clases altas con una discapacidad más límite. Considero que este debe ser el camino a la hora de plantear diferentes clases en el contexto de participación internacional para los deportistas con DI, tanto en VIRTUS como en el movimiento paralimpico y que tendría como consecuencia una mejora en la igualdad de oportunidades para este colectivo de personas (D. FEDDI).

MARIz $^{19}$ relata que a síndrome de Down é a síndrome genética mais frequente em todo o mundo, uma das principais causas da deficiência intelectual e que "relativamente ao desenvolvimento motor, e de uma forma geral, verifica-se um atraso no que diz respeito às competências motoras básicas, como o desenvolvimento postural, o equilíbrio e a força" (p. 46). A autora apresenta ainda que para dar respostas às necessidades de prática esportiva competitiva das pessoas com síndrome de Down em 2012 surge a Sports Union for Athletes with Down Syndrome, que tem como uma das missóes "o reconhecimento de uma nova classe específica para atletas com síndrome de Down, visando que o Comité Paralímpico a aplique nos Jogos paraolímpicos" (p. 53) ${ }^{19}$.

\section{Benefícios na participaçáo das pessoas com DI e SD}

O Movimento Paralímpico tem proporcionado a ascensão pessoal e social dos atletas com deficiência, proporcionando a possibilidade de tornar visível sua eficiência e proporcionando uma visão modificada para a sociedade ${ }^{1}$. O relato de atletas paralímpicos com diferentes deficiências ${ }^{1}$ apresentam o quanto o esporte paralímpico modifica sua vida e proporciona a valorizaçáo dessas pessoas na sociedade. O foco dado historicamente para a deficiência é direcionado para o esporte e para a eficiência no esporte.

Como vimos a atividade física pode trazer diversos benefícios para as pessoas com síndrome de Down $^{4-8}$. No entanto o esporte de alto rendimento competitivo também pode proporcionar para as pessoas com síndrome de Down os mesmos benefícios observados para pessoas com as deficiências legíveis nos Jogos Paralímpicos.

O principal e ter mais visibilidade internacional de um trabalho solidificado por anos pelas federaçóes, técnicos e atletas, também existe a questão da disparidade esportiva por ser ser o atleta com SD acometido de características completamente diferente dos demais D.I. E fato que no mundo já temos condiçōes de provar que existe competição e qualidade de treinamento em alto rendimento, além disso temos a comprovação da deficiência estabelecida e reconhecida pelos padróes internacional (D. CBDI).

La mayor participación de las personas con DI y los síndrome down supondría realmente que este colectivo tuviera una representación "parecida" al resto de colectivos de la discapacidad. Los JJPP presumen de ser el evento deportivo más importante para las personas con discapacidad. Los gobiernos de los países enfocan sus políticas deportivas,ayudas etc... en este evento y en todo lo que rodea a los eventos del IPC lo que se traduce en que las personas con DI tienen acceso muy muy reducido a todas las ayudas y beneficios que rodean este movimiento. Por otro lado, los deportistas con síndrome down ni siquiera tienen la opción de acceder a nada de esto. Al intentar igualar la representatividad de la DI en el contexto paralimpico e integrar a los síndrome de down estaríamos hablando de conseguir una igualdad representativa en este evento (D. FEDDI).

Muitas dificuldades ainda existem para ampliação e inclusão do esporte competitivo para pessoas com deficiência intelectual e não é diferente na Espanha.

Uno de los problemas actuales está siendo la integración del deporte para personas con discapacidad en las federaciones para personas sin discapacidad. Esto supone que las federaciones 
unideportivas trabajen únicamente las modalidades que se recogen en sus federaciones internacionales (FISA, UCI, ITU, etc.). Ninguna de ellas recoge modalidades para personas con DI y por tanto a nivel nacional estas federaciones (remo, ciclismo, triatlón, tenis) no fomentan ni trabajan el deporte para personas con DI. Esto se produce en muchas ocasiones porque el deporte se les ha trasladado desde IPC donde solo se contempla la DI en 3 deportes (Atletismo, Natación, Tenis Mesa). En los diferentes países existe un movimiento generalizado de incluir el deporte en estas federaciones y suprimir las federaciones específicas para personas con DI, las cuales son las que estaban adheridas a VIRTUS. Por lo tanto países como Holanda, Alemania, Suecia que eran países activos en VIRTUS han dejado de serlo... Además, en el caso específico de Espańa la focalización de los gobiernos hacia el contexto paralimpico hace que sólo puedan destinarse recursos económicos a los deportes de.atletismo y natación, no pudiendo desarrollar a nivel internacional otros deportes como fútsal, basket por no poder destinar recursos a ello (D. FEDDI).

No entanto alguns avanços podem ser observados no desenvolvimento do esporte para pessoas com deficiência intelectual no Brasil e na Espanha.

Tivemos muitos avanços principalmente no que se refere a qualidade das competiçóes, aprimoramento de treinamentos para cada área da deficiência intelectual e maior envolvimento dos técnicos na descoberta de talentos. $\mathrm{Na}$ área de classificação e elegibilidade a Virtus tem promovido periodicamente encontros de instrução para psicólogos e isso possibilitou um maior número de atletas no alto rendimento (D.CBDI).

En mi opinión la integración de las personas con DI en el movimiento paralimpico ha sido un paso atrás en la representatividad del colectivo en el ámbito del contexto de participación en los eventos internacionales. Muchos países han perdido las estructuras deportivas específicas para deportistas con DI y las federaciones unideportivas centran sus programas y esfuerzos en las modalidades y especialidades que se recogen en las federaciones internacionales unideportivas y eventos del IPC. Las entidades que trabajan en la igualdad de oportunidades para personas con DI son las específicas y las que además están vinculadas a VIRTUS. El deporte para personas con discapacidad está gestionado por el IPC y no por las federaciones internacionales como ocurre en el deporte para las personas sin discapacidad, el cual organiza eventos muy restrictivos anualmente en cuanto a oportunidades de participación. Cómo podemos pretender que las oportunidades de participación en competicion internacional de una persona con DI anualmente sea un evento al que se llama Campeonato del Mundo/ Europa donde solo pueden participar en $400 \mathrm{~m} / 1500 /$ peso/longitud... Si trasladamos esto a una persona sin discapacidad sería inconcebible... (D. FEDDI).

Sobre qual o objetivo e a maior realização que as instituiçóes pesquisadas do responsáveis pelo esporte de alto rendimento no Brasil e na Espanha buscam quanto a conquistas para o esporte para as pessoas com deficiência intelectual e síndrome de Down, verificamos que:

A maior conquista seria a inclusão de forma definitiva dos SD nas Paraolimpíadas, nosso objetivo e colaborar com processo da Virtus Sports e termos respostas mais rápidas dos estudos apoiados pelo IPC para essa inclusão (D. CBDI).

El mayor logro que tanto FEDDI como cualquier otra federación Nacional podría conseguir es que las personas con DI así como los síndrome de down tengan las mismas oportunidades de participación en el contexto internacional que cualquier persona sin discapacidad. Actualmente nos encontramos en un contexto muy restrictivo y en el que la linea que se está llevando no parece que se esté trabajando para que esto ocurra (D. FEDDI).

Silveira et $\mathrm{al}^{20}$ propóem que a Educação Física pense no movimento como um Direito Humano fundamental. Relatam que o movimento humano "tem uma importância fundamental para a vida: é por meio dele que o ser humano interage com o meio ambiente trocando matéria e energia” (p. 4). Incluir as pessoas com síndrome de Down nas paralimpíadas é uma forma de favorecer o movimento físico e esportivo, além de outros movimentos como a exposição midiática, atuação social, valorização cultural e acessibilidade atitudinal. 


\title{
Considerações finais
}

Finalizamos esse texto enfatizando a necessidade de maior participação das pessoas com deficiência intelectual e com síndrome de Down no esporte de alto rendimento e no maior evento competitivo mundial direcionado para as pessoas com deficiência: as paralimpíadas. Esse estudo apresenta um tema e abordagem não encontrados em outros estudos.

Com as paralimpíadas de 2020, sendo realizada durante a escrita desse artigo, pode-se reafirmar a eficiência dos atletas com deficiência física, visual e intelectual. A maior visibilidade é observada a cada paralimpíadas, com cada vez mais cobertura dos jogos paralímpicos pelas mídias, proporcionando para a sociedade uma nova visão da pessoa com deficiência e sua eficiência. A pouca participação das pessoas com deficiência intelectual e não participação da pessoa com síndrome de Down diminuem a possibilidade destas estarem incluídas na mudança de visão da sociedade, o que podemos caracterizar como negação de um direito humano de acesso e igualdade, previstos na Declaração Universal dos Direitos Humanos ${ }^{20}$.

Esperamos com esse estudo dispertar atenção e interesse de novos pesquisadores e pessoas envolvidas no movimento paralímpico para que essa realidade seja modificada e a inclusão das pessoas com deficiência intelectual e síndrome de Down seja tão efetiva quando das deficiências física e visual nas paralimpíadas.

\section{Agradecimentos}

Agradecimento ao Comitê Paralímpico Brasileiro, Confederação Brasileira de Desporte para pessoas com Deficiência Intelectual e Federação Espanhola de Desporte para Deficiência Intelectual.

\begin{abstract}
Participation of people with intellectual disabilities and Down syndrome in the Paralympics: the right to visibility.

The Paralympic Games are currently the moment of greater visibility for the efficiency of people with disabilitiesthroughsport.Theparticipation of peoplewith intellectual disabilities in theParalympics has been much lower than that of people with sensory or motor disabilities. And people with Down syndrome have been excluded from this event. This article aims to analyze the right to visibility and participation of people with intellectual disabilities and Down syndrome in theParalympics. This is a qualitative-descriptiveresearch carried out through a questionnaire with officials of the sports confederation for people with intellectual disabilities in Brazil and Spain. It was found that people with intellectual disabilities have less participation and people with Down syndrome are not participating in the paralympics. It is concluded that participation in the Paralympics is a right that, in addition to guaranteeing the right to movement and sport, can provide greater visibility for these people and possible changes in prejudice.
\end{abstract}

KEYWORDS: Human rights; Intellectual disability; Sport. 


\section{Referências}

1. Dalla Déa VHS et al. Visibilidade do esporte e atleta paraolímpico [Ebook]. Goiânia: Cegraf UFG, Coleção Inclusão, 2020. 2. Hilgemberg T. Jogos Paralímpicos: História, mídia e estúdios críticos da deficiência. Recorde. 2019;12(1):1-19.

3. Comitê Paralímpico Brasileiro. Conheça as modalidades e provas paralímpicas para pessoas com deficiência intelectual [Internet], 2021. Disponível em: https://cpb.org.br/noticia/detalhe/3102/conheca-as-modalidades-e-provas-paralimpicaspara-pessoas-com-deficiencia-intelectual.

4. Comité Paralímpico Español [Internet]. 2001. Disponível em: https:/www.paralimpicos.es/.

5. Modesto EL. Efeitos de dois programas de treinamento sobre a força muscular e o equilíbrio dinâmico de adolescentes com síndrome de Down [dissertação]. Universidade Estadual de Londrina. Centro de Educaçáo Física e Esporte. Programa de Pós-Graduação em Educação Física; 2014.

6. Seron BB. Efeitos de dois programas de treinamento sobre a capacidade cardiorrespiratória e a composição corporal de jovens com síndrome de Down [dissertação]. Universidade Estadual de Londrina. Centro de Educação Física e Esporte. Programa de Pós-Graduação em Educação Física; 2014.

7. Everaldo LM. Efeitos de dois programas de treinamento combinado sobre a composição corporal e cinemática da marcha de jovens com síndrome de Down [dissertação]. Universidade Estadual de Londrina. Centro de Educação Física e Esporte. Programa de Pós-Graduação em Educação Física; 2019.

8. Confederação Brasileira de Futebol. CBF e CBDI fecham acordo para levar Seleção de Futsal Down à Turquia [Internet]. Disponível em: https://www.cbf.com.br/a-cbf/informes/cbf-social/cbf-garante-participacao-da-selecao-de-futsal-downno-mundial.

9. Dellavia C, Pallavera A, Orlando F, Sforza C. Postural stability for athletes in Special olympic. Percept Mot Skills. 2009; 108:608-622.

10. De Luca CJ, Mambrito B. Voluntary control of motor units in human antagonist muscles: coactivation and reciprocal activation. J Neurophysiology. 1987;58:525-542.

11. Comitê Paraolímpico Brasileiro. Atletas com síndrome de Down têm classe exclusiva nas Paralimpíadas Escolares 2019 [Internet]. Disponível em: https://fb.watch/4wfusawHiV/

12. Bardin L. Análise de conteúdo. Lisboa: Ediçôes 70, 1977.

13. World Intellectual Impairment Sport - Virtus (2019). A guide to eligibility and classification for athletes with an intellectual disability [Internet]. Disponível em: https:/www.virtus.sport/aboutus/what-we-do/governance-handbook. acessado em 18/05/2020.

14. Burns J. The impact of intellectual disabilities on elite sports performance. Int Rev Sport Exercise Psychol. 2015;8(1):251267. Disponível em: http://dx.doi.org/10.1080/1750984X.2015.1068830.

15. Silva A, Narciso F, Stieler E, Facundo LA, Cruz AÂS, Costa AM, Silvestre P, Mello MT. Mapeamento geográfico de atletas paraolímpicos brasileiros. Movimento. 2019;25(e25052).

16. Alves A. Nadadores com síndrome de Down querem ter classificação própria: Atualmente competem com portadores de outras deficiências. Record, 2019. Disponível em: https://www.record.pt/modalidades/jogos-olimpicos/paralimpicos/ detalhe/nadadores-com-sindrome-de-down-querem-ter-classificacao-propria.

17. Querido A, Corredeira R, Daly D, Fernandes RJ. Início de ciclo paraolímpico: particularidades dos nadadores com Síndrome Down. 40 Congreso Técnico-científico da Associação Portuguesa de Técnicos de Natação. Universidade do Porto, 2017 [Internet]. Disponível em https://www.aptn.pt/tecnicos-natacao/sites/default/files/livrodeatasaptn2017final. pdf\#page $=37$

18. Leitão MTK. Perspectivas de atuação profissional: um estudo de caso das Olimpíadas Especiais I [tese]. Campinas, SP (Brasil): Universidade Estadual de Campinas; 2002.

19. Mariz M. O Papel do treinador na preparação psicológica de atletas com Síndrome de Down: estudo centrado na seleção nacional de natação. Dissertaçáo de mestrado. Porto: Faculdade de Desporto da Universidade do Porto, 2017.

20. Silveira SR, Freudenheim AM, Bassi P, Oliveira JÁ. Núcleo de Direitos Humanos da Escola de Educação Física e Esporte da USP: uma perspectiva educativa. Rev Bras Educ Fís Esporte. 2020;34(nesp):1-9. 


\begin{tabular}{r|c} 
ENDEREÇO & \\
Vanessa Helena Santana Dalla Déa & \\
Rua 1A, Quadra 19, Casa O2 & Submetido: 01/12/2021 \\
Chácara Recreio Samambaia & Aceito: 06/12/2021 \\
13741-340 - Goiânia - GO - Brasil & \\
E-mail: vanessasantana@ufg.br & \\
&
\end{tabular}

